\title{
Retrospective evaluation of primary anterior teeth injuries and prevalence of sequelae in their successors
}

\author{
Ozant Oncag $^{1} \bowtie$, (1) Candan Gurbuz Sarigol ${ }^{2}$, Sevgi Arabulan ${ }^{3}$
}

\section{Highlights}

Traumatic injuries of primary dentition are commonly seen in pediatric dental practice.
Trauma to primary dentition may cause sequelae in developing permanent dentition. It is important to know possible effects and detect as early as possible.
Early detection of any sequelae and regular follow ups help better prognosis and provide more convenient treatment.
${ }_{1}$ Professor, Department of Pediatric

Dentistry, School of Dentistry, Ege

University, Izmir, Turkey

2 Specialist, Alsancake Oral and Dental

Health Center, Izmir, Turkey

${ }^{3}$ Resident, Department of Pediatric

Dentistry, School of Dentistry, Ege

University, Izmir, Turkey

\section{Correspondence:}

Department of Pediatric Dentistry, School of Dentistry, Ege University, Izmir, Turkey.

E-mail address:

ozantoncag@gmail.com

\section{Abstract}

Aim: Traumatic dental injuries occur frequently in children. Treatment and follow ups are important to avoid short and long term complications. The aim of this study was to investigate the prevalence of sequelae in the permanent anterior teeth following the trauma in their predecessors in the period of 2005 to 2011. Methods: This study was performed retrospectively according the data from the records of 79 children (53 boys, 26 girls), who were treated for anterior deciduous tooth trauma. Of the 79 affected children (186 teeth), 35 (91 teeth, 22 boys and13 girls) were available for the follow-up examination. Kappa coefficient was calculated for inter-examiner reliability. Descriptive statistics including percentage and mean values were also calculated. Results: Sequelae were detected on $45(49.5 \%)$ of 91 successors of the traumatized deciduous teeth and enamel hypoplasia and/or discoloration was observed in $14(31.1 \%)$ teeth. Eruption was disturbed in $14(31.1 \%)$. In 13 teeth $(28.9 \%)$ crown and root malformation, in three teeth $(6.7 \%)$ only crown and in one tooth $(2.2 \%)$ only root malformation was detected. Most frequent sequela of successors were observed after the intrusive luxation of the deciduous teeth $(33 \%)$. Crown-root malformations of the successor teeth were most frequently occurred after the trauma at the age of 0 to $2(61.53 \%)$. Conclusions: Early diagnosis and treatment of primary dental injuries and routine clinical and radiological follow up would minimize the sequelae which were observed in permanent successors.

Keywords: Dental Trauma; Primary Teeth; Sequela; Tooth Injuries

Received: 10 January 2021

Accepted: 25 March 2021

Online First: 01 April 2021 


\section{INTRODUCTION}

Dental trauma in children and adolescents is a common and serious problem. This injury has a high rate of incidence in deciduous teeth among children in the motor development phase. ${ }^{1-3}$ During this period, falls or tumbles are the most common reason ${ }^{4}$ and the most affected teeth are the upper deciduous central incisors. ${ }^{5-7}$ Different types of traumatic injuries affect the primary dentition. However, primary incisors are highly liable to luxation injuries, which constitute the $21 \%$ to $81 \%$ of traumatic injuries of these teeth. ${ }^{8-9}$ Due to the close relationship between the apices of the primary teeth and the germs of their permanent successors, developmental disturbances in the permanent dentition are common after trauma of the primary teeth, varying from $12 \%$ to $74 \% .{ }^{10-12}$ The severity of the sequela depends on the age of the child at the time of injury, the grade of root resorption of the traumatized deciduous tooth, the type and extent of the injury, and the developmental stage of the successor at the time of injury. ${ }^{12-13}$ Traumatic avulsion and intrusive luxation are the most frequent types of trauma that affect the development of permanent successors. ${ }^{9}$ The sequelae in permanent teeth caused by traumatic injury in their predecessors are registered according to the following classifications: white or yellow-brown discoloration of enamel, enamel hypoplasia, crown dilaceration, root dilaceration, odontoma-like malformation, root duplication, partial or complete arrest of root formation, sequestration of the permanent tooth germ and eruption disturbances. The discoloration of enamel and the enamel hypoplasia are the most frequent sequelae. ${ }^{12-14}$ The treatment strategy after traumatic injuries of the primary dentition is determined by the concern for the safety of the permanent dentition. ${ }^{15-22}$

Management of traumatic dental injuries in children is challenging for both the child and the parents. It can also be challenging for the dental team. Correct treatment and follow-up are important to give the child the best possible dental care. The risk of long-term complications may - if left affect the permanent teeth if left untreated. Thus, the aim of this study was to investigate the prevalence of sequelae in permanent anterior teeth following trauma in their predecessors.

\section{METHODS}

This study was approved by the Ege University Clinical Research Ethics Committee (20-3.1T/58).

This retrospective study was based on the clinical data of 79 patients (186 teeth). Of the 79 children (53 boys, 26 girls) who were treated for anterior primary tooth trauma in our university, a follow-up examination on 35 patients (91 teeth) were performed for the period of 2005 to 2011. Patients were recalled before for examination every 3-6 weeks, 3 months, 6 months and annually. The inclusion criteria were as follows; aged between 0-6 years at the time of injury; anterior primary tooth injuries; no systemic disease involvement; no medication taken; and attendance of regular follow up visits for 6 years. Clinical and radiological examinations data were evaluated for each patient retrospectively. The age, gender, etiology and time of trauma, presence or absence of soft tissue injury, number of injured teeth, type of trauma and type of tooth were investigated. The type of trauma was recorded according to the classification criteria of Andreassen and Andreassen. ${ }^{9}$ During the followup examination evaluations of 35 patients (91 teeth), clinical examinations and dental radiographs were investigated for each patient. The following information was determined: presence or absence of sequelae on permanent tooth, type of sequelae (hypoplasia, crown-root malformation, crown or root malformation), time of eruption of the permanent tooth (normal, delayed, premature), and the presence or absence of displacement. When the tooth presented more 
than one sequela, the most serious one was taken into consideration. All children were examined, assisted and followed up by a paediatric dentistry postgraduate student who had previously been trained and supervised by the same professor from the department. Examinations were performed with mirror and probe assisted by artificial light.

\section{Statistical analysis}

The data were analyzed using SPSS (Statistical Package for the Social Sciences) 20.0 version. Ten percent of the principal investigator's sample was randomly assessed by the supervisor to check inter-examiner reliability in recording data. The Kappa inter-examiner reliability score was 0.98 . Descriptive statistics including percentage and mean values were also calculated.

\section{RESULTS}

The prevalence of traumatic dental injuries was higher in boys $(67 \% .1 / 53$ patients $)$ in comparison to girls $(32.9 \% / 26$ patients). The distribution of the patients according to their age is presented in Figure 1 where it can be noted that the highest frequency of trauma occurred in the 2to 4-year age group. The percentage of the injuries with regard to aetiology and season are summarized in Table 1.

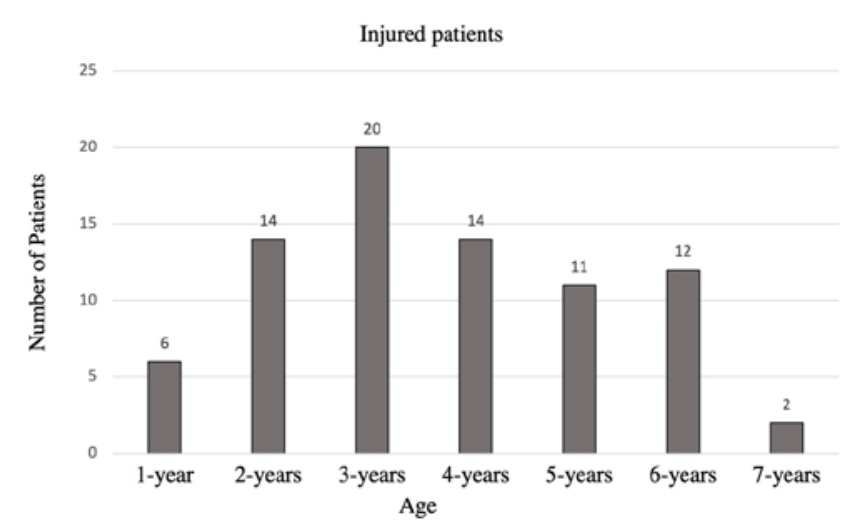

Figure 1. Age range of examined patients

Table 1. The distribution of injuries with regard to etiology and season

\begin{tabular}{llll}
\hline $\begin{array}{l}\text { Etiology of } \\
\text { Trauma }\end{array}$ & $\begin{array}{l}\text { Number of } \\
\text { Patients } \\
\mathbf{n ~ ( \% )}\end{array}$ & Season & $\begin{array}{l}\text { Number of } \\
\text { Patients } \\
\mathbf{n}(\mathbf{\%})\end{array}$ \\
\hline Falls & $43(54.4 \%)$ & Winter & $19(24.1 \%)$ \\
Collisions & $32(40.5 \%)$ & Spring & $22(27.8 \%)$ \\
Road accident & $4(5.1 \%)$ & Summer & $30(38 \%)$ \\
& & Autumn & $8(10.1 \%)$ \\
\hline
\end{tabular}

In these 79 patients, 186 deciduous teeth were affected by trauma. The most common type of traumatized teeth was those in the maxillary arch $(91.3 \%)$. The distribution of injuries regarding the affected teeth is summarized in Figure 2.

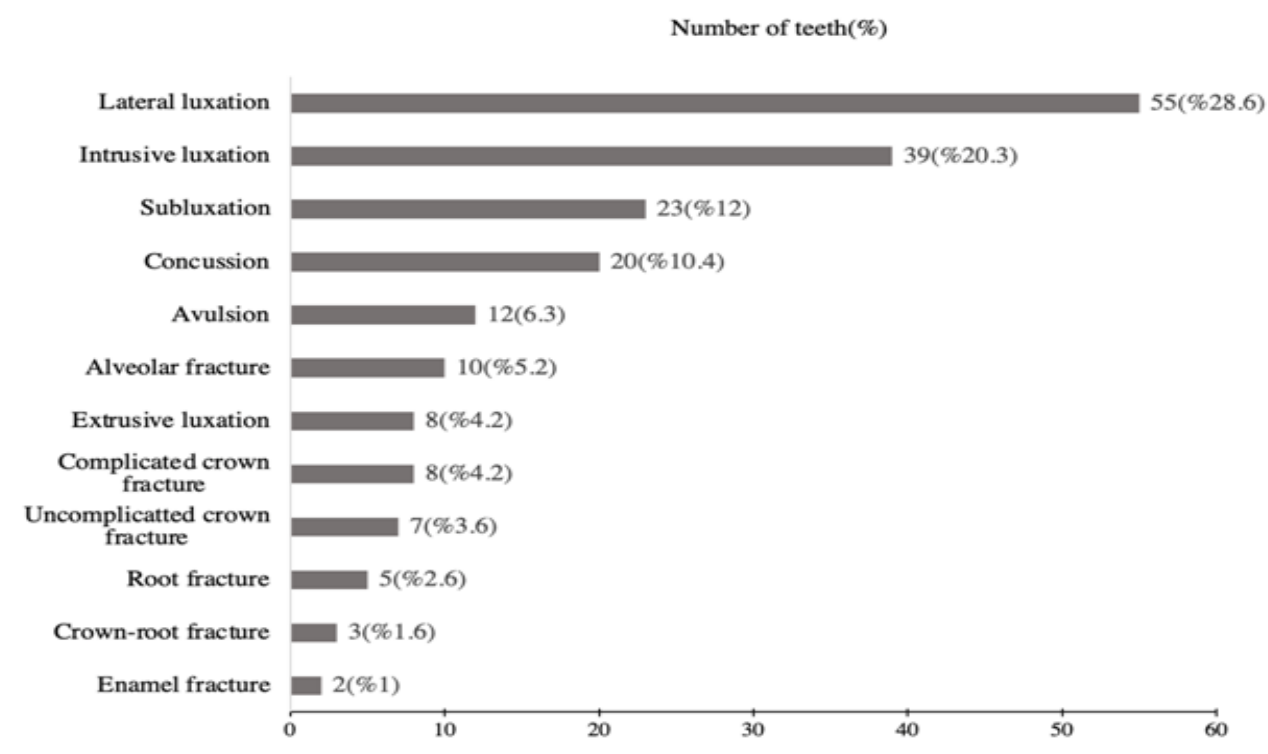

Figure 2. The distribution of dental injuries 
The most commonly affected teeth were the maxillary right $(36 \%)$ and left deciduous central incisors $(36 \%)$. Six teeth were affected by more than one type of injury and a total of 192 individual injuries were designated. In this study, the range of dental injuries according to Andreasen's classification is presented in Figure 2.9 The most common type of injury was luxation injuries $(75.5 \%)$, which can be subdivided into concussion, subluxation, lateral luxation, extrusive luxation and intrusive luxation. Among the luxation injuries, the most common type of injuries were lateral luxation (28.6\%) and intrusive luxation (20.3\%) respectively (Figures 3 and 4).

Of the 79 affected children (186 teeth), follow-up examination data for a 6 -year period for 35 patients (91 teeth) were available. Of these 35 patients, 22 were boys $(62.9 \%)$ and 13 were girls $(37.1 \%)$. Of the 91 teeth which were followed up, damage was detected on 45 permanent teeth
(49.5\%). Among these 45 damaged permanent teeth, 9 teeth had more than one type of sequelae. The distribution of these sequelae is presented in Table 2.

Table 2. The distribution of sequelae

\begin{tabular}{ll}
\hline Sequela & $\begin{array}{l}\text { Number of teeth } \\
(\mathbf{n}=\mathbf{4 5})\end{array}$ \\
\hline Hypoplasia & $12(26.6 \%)$ \\
Irregular eruption & $14(31.1 \%)$ \\
Crown-root malformation & $12(26.6 \%)$ \\
Crown malformation & $3(6.6 \%)$ \\
Root malformation & $4(8.8 \%)$ \\
\hline
\end{tabular}

Enamel hypoplasia was found as discoloration in $9(20 \%)$ teeth; and in $3(6.6 \%)$ teeth, a combination of discoloration and faults in the enamel were observed (Figure 3a).

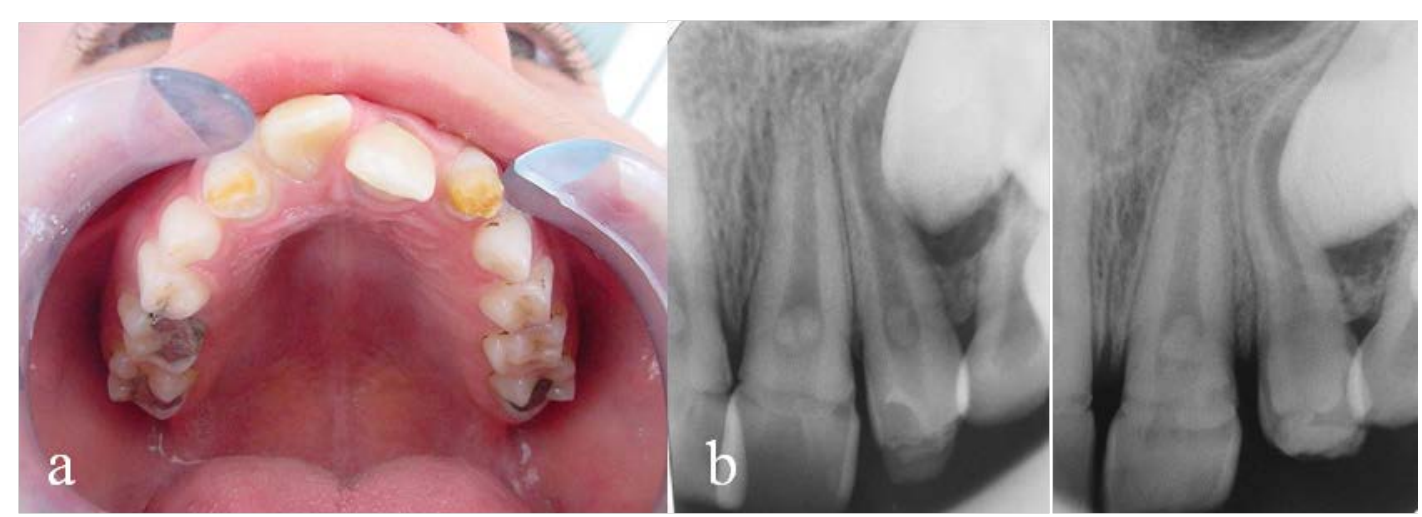

Figure 3. a) Crown malformation of the tooth 21 and enamel hypoplasia of the teeth 12, 22 following avulsion of the tooth 61 and lateral luxation of teeth 51, 52, 62

b) Furthermore pulp stone formation in the radicular pulp of the teeth

Eruption disturbance was detected in 14 (31.1\%) teeth. In $11(24.4 \%)$ teeth, eruption was delayed without displacement and in three teeth, eruption was delayed with displacement. Seventeen teeth of permanent dentition showed malformations; in 12 $(26.6 \%)$ teeth crown and root malformation (Figures 3,4, 5 and 6), in three (6.6\%) teeth, only crown malformation and in four (8.8\%) teeth, only root malformation (Figure 7 ) were detected.

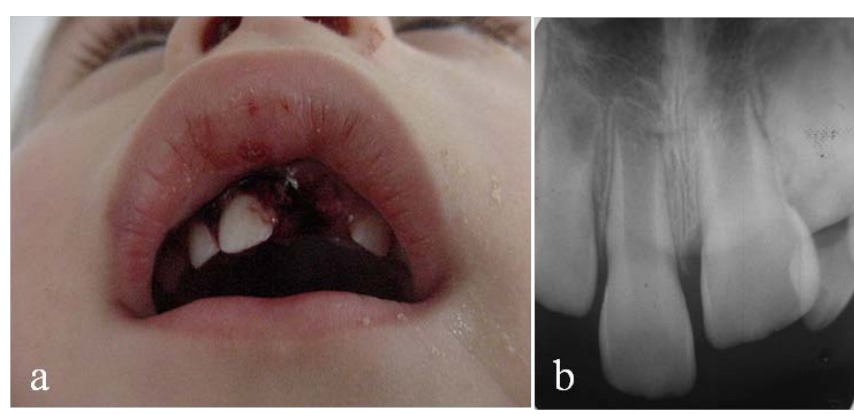

Figure 4. a) Intrusive luxation of the teeth 61, 62 and lateral luxation of the teeth 51,52 at 2 years of age.

b) Following this trauma at the age of 2, partial arrest of root formation of the tooth 21 at the age 8 


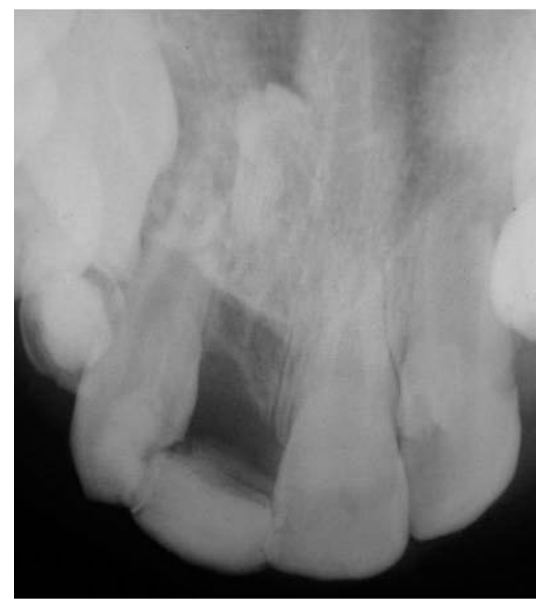

Figure 5. Crown and root malformation of tooth no. 11, following the intrusive luxation of the teeth 51,52 at the age of 14

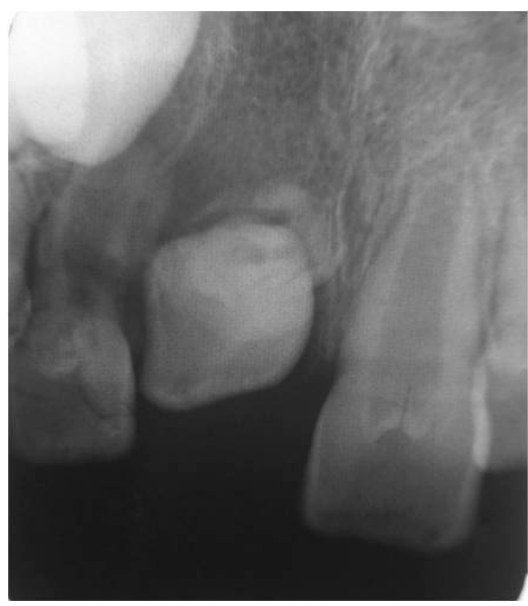

Figure 6. Severe crown and root malformation of the tooth 11 following the intrusive luxation of the teeth 51 and 52 at the 19 months old child

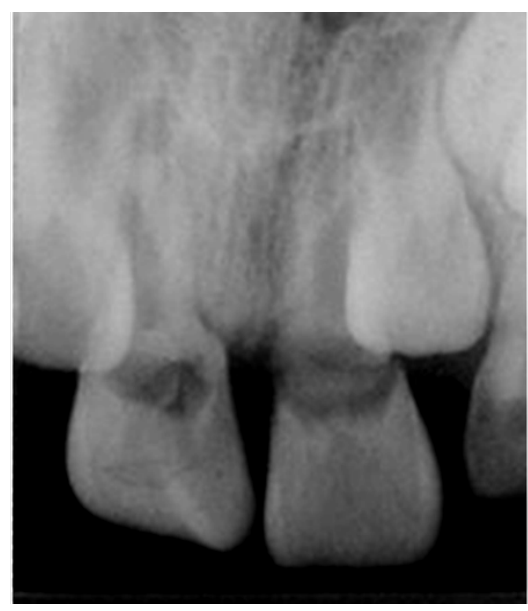

Figure 7. Complete arrest of root formation of the teeth 11 and 21 following intrusive luxation of the teeth 51 and 61 at the age of 2
The number of teeth which were followed up and the type of the trauma is related to the secondary damage is shown in Table 3. Secondary damage was most frequently caused by intrusive luxation injuries (Table 3). The crown-root malformation was most frequently detected after the intrusive luxation (Table 3).

Table 3. Type of injury affecting the primary dentition, and sequela affecting the successors

\begin{tabular}{|c|c|c|c|c|}
\hline Type of injury & $\begin{array}{l}\text { Number of } \\
\text { teeth }\end{array}$ & $\begin{array}{l}\text { Number of } \\
\text { followed teeth }\end{array}$ & Sequelae & $\begin{array}{l}\text { Number of } \\
\text { teeth }\end{array}$ \\
\hline \multirow[t]{5}{*}{ Intrusive luxation } & $20(21.9 \%)$ & $15(33.3 \%)$ & Hypoplasia & 2 \\
\hline & & & Crown-root malformation & 7 \\
\hline & & & Crown malformation & 2 \\
\hline & & & Root malformation & 3 \\
\hline & & & Irregular eruption & 1 \\
\hline \multirow[t]{3}{*}{ Lateral luxation } & $23(26.2 \%)$ & $9(20 \%)$ & Hypoplasia & 6 \\
\hline & & & Crown-root malformation & 1 \\
\hline & & & Irregular eruption & 2 \\
\hline \multirow[t]{2}{*}{ Subluxation } & $16(17.4 \%)$ & $7(15.55 \%)$ & Crown-root malformation & 2 \\
\hline & & & Irregular eruption & 5 \\
\hline \multirow[t]{3}{*}{ Avulsion } & $8(8.7 \%)$ & $6(13.33 \%)$ & Crown-root malformation & 2 \\
\hline & & & Crown malformation & 1 \\
\hline & & & Irregular eruption & 3 \\
\hline \multirow[t]{2}{*}{ Extrusive luxation } & $7(7.6 \%)$ & $4(8.88 \%)$ & Hypoplasia & 3 \\
\hline & & & Root malformation & 1 \\
\hline Concussion & $9(9.7 \%)$ & $2(4.44 \%)$ & Irregular eruption & 2 \\
\hline $\begin{array}{l}\text { Complicated crown } \\
\text { fracture }\end{array}$ & $6(6.4 \%)$ & $2(4.44 \%)$ & Hypoplasia & 1 \\
\hline Uncomplicated crown fracture & $2(2.1 \%)$ & $0(0 \%)$ & Irregular eruption & 1 \\
\hline
\end{tabular}


After the trauma of the primary dentition, especially between the ages of 2 to 4 years, sequelae frequently occurred $(48.9 \%)$ in the permanent teeth (Table 4).

Table 4. Number and percentage of sequelae according to age

\begin{tabular}{lll}
\hline $\begin{array}{l}\text { Age of child at } \\
\text { time of injury }\end{array}$ & $\begin{array}{l}\text { Number of } \\
\text { patients with } \\
\text { sequelae }\end{array}$ & $\begin{array}{l}\text { Percentage of } \\
\text { patients with } \\
\text { sequelae }\end{array}$ \\
\hline 0-2 years & 14 & $31.10 \%$ \\
2-4 years & 22 & $48.90 \%$ \\
4-6 years & 9 & $20 \%$ \\
\hline
\end{tabular}

The relationship between patients' age at the time of trauma and the kind of development disturbances is presented in Figure 8. After trauma between the ages 0 to 2 years, the most commonly occurring sequela was crown-root malformation. Irregular eruption and hypoplasia were detected at high rate between the ages of 2 to 4 years and 4 to 6 years (Figure 8 ).

\section{DISCUSSION}

Traumatic injuries of the deciduous dentition are the most important physical factors that can disturb permanent tooth formation. ${ }^{20,21}$ This study was conducted to evaluate prevalence of sequelae in the permanent anterior teeth after trauma in their predecessors. In this study, $49.5 \%$ of the successors presented some developmental disturbances. Furthermore, the most severe malformations of the successors occurred in those children aged between 0 and 4 years of age at the time of injury. ${ }^{16,19}$ In this study, the most frequently detected sequelae in the successor teeth were tooth malformations (Crown-root malformation, crown malformation and root malformation).

The germs of the permanent incisors are positioned palatally and in very close proximity to the roots of their predecessors. ${ }^{22}$ As a result of this close anatomical relationship, traumatic injuries in anterior primary teeth can lead to developmental disturbances in the permanent teeth. $6,13,19$

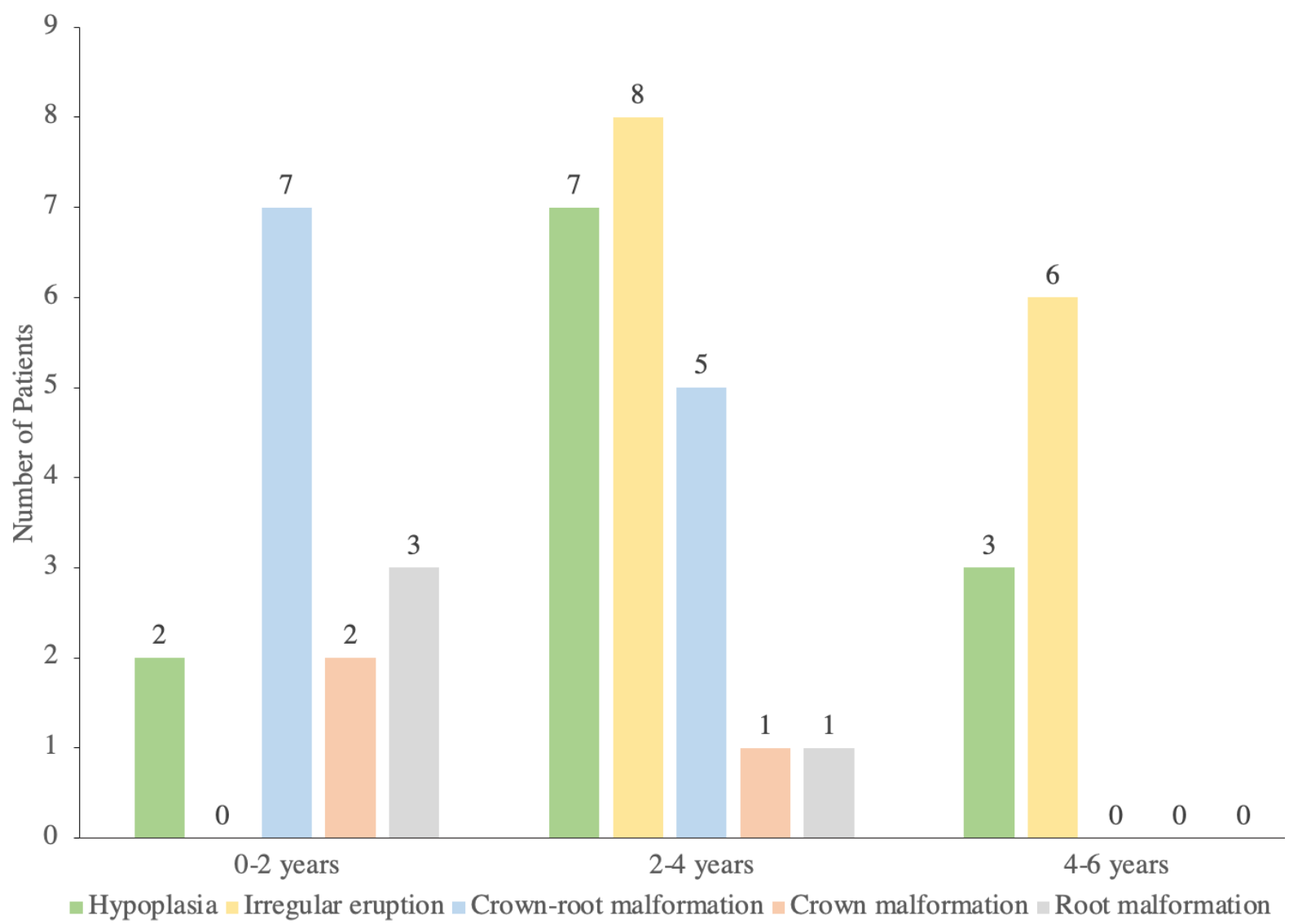

Figure 8. Relationship between the age of patients' at the time of injury and the type of sequela 
The level of developmental disturbance in the permanent tooth depends on the stage of odontogenesis of the permanent tooth and the impact intensity and direction of the dental trauma. ${ }^{23}$

The number of trauma cases increases during the summer period. Results of this study match the results of previous studies conducted in Turkey.24, 25 This finding could be attributed to the fact that outdoor activities increase with warmer weather. In agreement with previous studies, we found a higher trauma percentage among boys than girls. ${ }^{26-28}$ This could be explained by the tendency of boys to take part in more dynamic outdoor activities compared to girls. As pointed out in another study ${ }^{24}$, Turkish society tends to raise girls in a more protective manner than boys. This could explain why boys have a higher percentage of traumatic injuries. Taking the age of the children at the time of accident into consideration, it becomes apparent that $80 \%$ of patients up to the age of 4 years suffered from sequelae in contrast to only $20 \%$ of patients older than 4 years. According to the previous studies, a possible cause could be the incomplete level of mineralization of bone and dental germ at that time. ${ }^{16,29-31}$ Moreover, in this research, irregular eruptions were considered as secondary sequela. 19,32 Although only the most serious sequelae were considered for classification, this type of secondary disturbance presented a high prevalence (31.1\%). Crown malformation of the permanent teeth is more common following an intrusive luxation or avulsion of primary teeth, and the most vulnerable period is the early ages. $914,19,22,32-34$ The results of this study regarding the age of children at the time of injury and the type of traumatic injury are similar to those reported in the literature. 9,14,22,34 Within the scope of this research, it is noted that root malformation was observed in 4 of the 45 permanent successors. From these 4 teeth with root malformation, 3 were caused by intrusion in children aged between
2 and 4 years age. Crown-root malformation is the most common sequela $(26.6 \%)$ in the tooth malformation. Predominantly, it is caused by intrusive luxations and avulsions in children between the ages of 0 to 2 years at the time of injury. ${ }^{11,19,35,36}$ In this study, similar to previous studies, it was found that intrusive luxation in primary teeth were the types of injury that most commonly caused sequela in their successors. ${ }^{8-12}$ Dental injuries are more common among preschool children. ${ }^{37}$ During this period, the permanent incisors are in continuous formation and any trauma can harm their constitution at different levels. The type of traumatic primary tooth injury connected with the age of the child at the time of accident can determine the possibility of subsequent secondary damages. Therefore, the importance of careful examination and documentation of the accident becomes significant. The purpose of the treatment of traumatic injuries in primary teeth can be regarded as an attempt to avoid major consequences in the involved tooth, and most importantly, to its developing successor. ${ }^{38}$ However, when the teeth and their surrounding tissues do not have any evident damage, parents only visit a dentist when a post traumatic sequela appears. ${ }^{19}$ In the aftermath of deciduous tooth trauma in children, the primary objective should be averting or minimizing the sequelae. Consequently, regular clinical follow-up examinations and periodic radiographs are necessary after the traumatic injuries of the deciduous teeth. However, one of the biggest difficulties in this study was to reach all previously traumatized patients. We determined that after the initial panic fades away, parents frequently do not come back for recall visits as other researchers have also pointed out. ${ }^{39,40}$ With regular follow-ups, early detection of any sequelae in the permanent anterior teeth can be established. Therefore, this approach can lead to a better prognosis which can minimize or avert the post traumatic sequelae in children and provide the possibility of a more effective treatment. 


\section{REFERENCES}

1. Andreasen JQ, Ravn JJ. Epidemiology of traumatic dental injuries to primary and permanent teeth in a Danish population sample. Int J Oral Surg 1972;1:235-239

2. Garcia-Godoy F, Garcia-Godoy F OM. Injuries to primary and permanent teeth treated in a private paedodontic practice. J Can Dent Assoc (Tor) 1979;45:281-284

3. Kramer PF, Zembruski C, Ferreira SH, Feldens CA. Traumatic dental injuries in Brazilian preschool children. Dent Traumatol 2003;19:299_ 303

4. Flores MT. Traumatic injuries in the primary dentition. Dent Traumatol 2002;18:287-298

5. Cardoso M, De Carvalho Rocha MJ. Traumatized Primary Teeth in Children Assisted at the Federal University of Santa Catarina, Brazil. Dent Traumatol 2002;18:129-133

6. Bijella MF, Yared FN, Bijella VT, Lopes ES. Occurrence of primary incisor traumatism in Brazilian children: a house-by-house survey. ASDC J Dent Child. 1990;57:424-427

7. Ferguson FS, Ripa LW. Prevalence and type of traumatic injuries to the anterior teeth of preschool children. J Pedod 1979;4:3-8

8. Garcia-Godoy F, Garcia-Godoy, F, Garcia-Godoy, FM. Primary teeth traumatic injuries at a private pediatric dental center. Dent Traumatol 1987;3:126-129

9. Andreasen JO, Andreasen FM. Avulsion. In Textbook and color atlas of traumatic injuries to the teeth. Denmark: Blackwell Publishing; 1994. p.457-494

10. Ben Bassat Y, Fuks A, Brin I, Zilberman Y. Effect of trauma to the primary incisors on permanent successors in different developmental stages. Pediatr Dent 1985;7:37-40

11. Diab M, elBadrawy HE. Intrusion injuries of primary incisors. Part III: Effects on the permanent successors. Quintessence Int 2000;31:377-384

12. von Arx T. Developmental disturbances of permanent teeth following trauma to the primary dentition. Aust Dent J 1993;38:1-10

13. Ben-Bassat Y, Brin I, Zilberman Y. Effects of trauma to the primary incisors on their permanent successors: multidisciplinary treatment. ASDC J Dent Child 1989;56:112-116

14. Andreasen JO, Ravn JJ. The effect of traumatic injuries to primary teeth on their permanent successors. II. A clinical and radiographic follow-up study of 213 teeth. Scand J Dent Res 1971;79:284-294

15. Andrade MGS, Weissman R, Oliveira MG, Heitz C. Tooth displacement and root dilaceration after trauma to primary predecessor: An evaluation by computed tomography. Dent Traumatol 2007;23:364-367

16. Sennhenn-Kirchner S, Jacobs HG. Traumatic injuries to the primary dentition and effects on the permanent successors - A clinical follow-up study. Dent Traumatol 2006;22:237-241

17. Lenzi AR, Medeiros PJ. Severe sequelae of acute dental trauma in the primary dentition - A case report. Dent Traumatol 2006;22:334-336

18. Moura LDFADD, Bezerra ACB, Amorim L de $F$ de G, Moura M de D, Toledo O de A. Intrusive luxation of primary teeth. Dent Traumatol 2008;24:91-95

19. Do Espirito Santo Jacomo DR, Campos V. Prevalence of sequelae in the permanent anterior teeth after trauma in their predecessors: A longitudinal study of 8 years. Dent Traumatol 2009;25:300-304

20. Lin Y. Treatment of an impacted dilacerated maxillary central incisor. Am J Orthod Dentofacial Orthop 1999;115:406-409

21. Shah N. Extraoral tooth eruption and transposition of teeth following trauma. Dent Traumatol 1994;10:195-197

22. Maragakis MG. Crown dilaceration of permanent incisors following trauma to their primary predecessors. J Clin Pediatr Dent. 1995;20:49-52

23. Prabhakar AR, Reddy V V, Bassappa N. Duplication and dilaceration of a crown with hypercementosis of the root following trauma: a case report. Quintessence Int 1998;29:655-657

24. Atabek D, Alaçam A, Aydintuğ I, Konakoğlu G. A retrospective study of traumatic dental injuries. Dent Traumatol 2014;30:154-161

25. Eyuboglu O, Yilmaz Y, Zehir C, Sahin H. A 6 -year investigation into types of dental trauma 
treated in a paediatric dentistry clinic in Eastern Anatolia Region, Turkey. Dent Traumatol 2009;25:110-114

26. Zuhal K, Semra ÖEM, Hüseyin K. Traumatic injuries of the permanent incisors in children in southern Turkey: A retrospective study. Dent Traumatol 2005;21:20-25

27. Cavalcanti AL, Bezerra PKM, De Alencar CRB, Moura C. Traumatic anterior dental injuries in 7- to 12-year-old Brazilian children. Dent Traumatol 2009;25:198-202

28. Güngör HC, Uysal S, Altay N. A retrospective evaluation of crown-fractured permanent teeth treated in a pediatric dentistry clinic. Dent Traumatol 2007;23:211-217

29. Ravn JJ. Sequelae of acute mechanical traumata in the primary dentition. A clinical study. ASDC J Dent Child 1968;35:281-289

30. Selliseth NE. The significance of traumatised primary incisors on the development and eruption of permenent teeth. Eur Orthod Soc 1970;443459

31. Watzek G SJ. Milchzahntraumen und ihre Bedeutung für die bleibenden Zähne. Zahn Mund Kieferheilkd. 1976;64:126-133

32. Andreasen JO, Andreasen F. Injuries to primary teeth. In: Andreasen JO, Andreasen F. Essentials of Traumatic Injuries to the Teeth: A Step-by-Step Treatment Guide. Denmark: Munksgaard; 2001. p.141-154

33. Andreasen JO, J. RJ. Enamel changes in permanent teeth after trauma to their primary predecessors. Scand J Dent Res 1973;81:203-209

34. Ravn JJ. Developmental disturbances in permanent teeth after intrusion of their primary predecessors. Scand J Dent Res 1976;84:137-141

35. Zilberman Y, Fuks A, Ben Bassat Y, Brin I, Lustmann J. Effect of trauma to primary incisors on root development of their permanent successors. Pediatr Dent 1986;8:289-293

36. Nolla CM. The developmental of permanent teeth. J Dent Child 1960;27:254-266

37. Kilpatrick NM, Hardman PJ, Welbury RR. Dilaceration of a primary tooth. Int J Paediatr Dent 1991;1:151-153

38. Oliveira,BH; Moliterno,LF; Marcl, S; Balda A. Intrusão de incisive decíduos provocando distúrbio no desenvolvimento de dentes permanents: relato de caso. Rev Bras Odontol 1995;52:42-45
39. Da Silva Assuñão LR, Ferelle A, Iwakura MLH, Cunha RF. Effects on permanent teeth after luxation injuries to the primary predecessors: A study in children assisted at an emergency service. Dent Traumatol 2009;25:165-170

40. Brin I, Fuks A, Ben-Bassat Y, Zilberman Y. Trauma to the Primary Incisors and Its Effect on the Permanent Successors. Pediatr Dent 1984;6:78-82

\section{How to cite this article:}

Ozant Oncag, Candan Gurbuz Sarigol, Sevgi Arabulan. Retrospective evaluation of primary anterior teeth injuries and prevalence of sequelae in their successors. Contemp Pediatr Dent 2021:2(1):41-49

\section{Declarations}

Acknowledgements: Not applicable.

Conflict of Interest Statement: The authors disclose no potential conflicts of interest.

Ethics Statement: This study was approved by the Ege University Clinical Research Ethics Committee (203.1T/58).

Informed Consent: Informed consent and assent were obtained from all participants.

Author contributions: Conception and design: All Authors; Acquisition of data: All Authors; Interpretation of data: All Authors; Drafting article: All Authors; Revision artice: All Authors; Final approval: All Authors

Funding: This work is not finantiated.

Data Availability: The data used to support the findings of this study can be made available upon request to the corresponding author.

Peer-review: Externally double-blinded peer-reviewed. 